\title{
Using Inclusive Sport for Social Change in Malawi, Africa
}

\author{
Patricia J. Craig \\ Bob Barcelona \\ Semra Aytur \\ Jess Amato \\ Sarah J. Young
}

\section{Abstract}

This report draws upon the first year of the Youth Enrichment through Sports (YES)-Africa cooperative agreement focused on sport for social change involving five sub-Saharan African countries. The YES-Africa program, funded by the U.S. Department of State, is designed to enhance cross-cultural understanding and collaboration between individuals and nations. The YESAfrica Malawi exchange builds capacity for sport leaders in Malawi to implement inclusive sport and recreation for youth with disabilities. This case study employs a content analysis of international and national legislative and policy agendas addressing inclusion of youth with disabilities within the context of sport, and explores barriers to policy implementation through interviews with seven key stakeholders and a review of structured field notes. Findings suggest that while Malawi's legislative and policy landscape appears to adequately address the needs of youth with disabilities broadly, implementation is limited by social, physical, and socio-environmental barriers. We explore contributions of TR professionals in addressing key policy priorities in developing countries.

Patricia J. Craig is an associate professor in the Department of Recreation Management and Policy at the University of New Hampshire.

Bob Barcelona is an associate professor and chair of the Department of Recreation Management and Policy at the University of New Hampshire.

Semra Aytur is an associate professor in the Department of Health Management and Policy at the University of New Hampshire.

Jess Amato is a CTRS/L and program director of Northeast Passage's school-based Recreational Therapy program at the University of New Hampshire.

Sarah J. Young is an associate professor and interim chair of Recreation, Park, and Tourism Studies in the School of Public Health at Indiana University, Bloomington.

Please send correspondence to Patricia J. Craig, pjcraig@unh.edu 


\section{Keywords}

Inclusive youth sport, Malawi, Africa, therapeutic recreation, United Nations' Sustainable Development Goals

\section{Using Inclusive Sport for Social Change in Malawi, Africa}

The United Nations (U.N.) has published 17 Sustainable Development Goals (SDGs) to guide global development with respect to poverty, gender equality, health and wellness, hunger, education, and sustainable use of natural resources to ensure that "no one is left behind" by 2030 (U.N., 2016). Included in the U.N. report are persons with disabilities, who are among the marginalized groups of people who are most likely to be "left behind," despite comprising approximately 15\% (1 billion people) of the world's population (WHO \& World Bank, 2011). Vulnerability related to and deriving from disability is partly inherent and partly generated by societal, cultural, legal, and physical barriers (Beqiraj, McNamara, \& Wicks, 2017). While the SDGs provide guidelines for countries to adopt in accordance with their own priorities and challenges, critics caution that we must remain vigilant regarding how the SDGs are operationalized and implemented by U.N. member states (Brolan, 2016). This is particularly important in the context of the U.N.'s Convention on the Rights of Persons with Disabilities (2006), which must be effectively integrated into policy and planning landscapes.

Therapeutic recreation (TR) and adaptive sport professionals are well positioned to advance the disability rights dialogue by promoting sport as an effective means for fostering positive health and well-being, social inclusion, and community building for persons with disabilities (International Platform on Sport \& Development, 2009). In this respect, sport has both individual and collective public health benefits. At the individual level, sport is linked to holistic health outcomes for individuals with disabilities, such as improved physical fitness, independence, teamwork and leadership skills, social connections, identity formation, and empowerment (Harada \& Siperstein 2009; International Platform on Sport \& Development; Lundberg, Taniguchi, McCormick, \& Tibbs, 2011; Rimmer, Rowland, \& Yamaki, 2007; Sherrill \& Williams, 1996). In a public health context, making sport more inclusive and developing more accessible community environments benefits the whole population, and not just persons with disabilities. For example, inclusive sport opportunities raise awareness among the general population of the unique strengths, capacities, and challenges faced by people with disabilities (Struthers, 2011; Wilhite \& Shank, 2009), and may enable persons with disabilities to contribute to economic and civic life (International Platform on Sport \& Development). Further, inclusive sport opportunities are associated with multiple intersectional co-benefits with respect to reducing poverty while facilitating equality, economic/civic participation, gender equity, educational achievement, preventing chronic (non-communicable) and infectious disease, promoting awareness for sustainable infrastructure, and generating cross-sectorial global/local partnerships (Sustainable Development Goal Fund, 2018).

The Youth Enrichment through Sports (YES)-Africa cooperative agreement focuses on sport for social change involving five sub-Saharan African countries. The YES-Africa program, funded by the Sports Diplomacy division of the Bureau of Edu- 
cational and Cultural Affairs (ECA) in the United States Department of State, is designed to enhance cross-cultural understanding and collaboration between individuals and nations (Bureau of Educational and Cultural Affairs [ECA], n.d.). The sub-award collaborative between the School of Public Health at Indiana University Bloomington and the University of New Hampshire focuses on Malawi. The YES-Africa Malawi sport exchange is designed to address many barriers to the implementation of Malawi's legislative and policy agenda related to youth, particularly around the area of capacitybuilding activities for key stakeholders and community leaders.

This study is part of a larger multi-stage, multi-method study examining outcomes of the YES-Africa Malawi program. The purpose of this study report is two-fold: (1) to explore Malawi's legislative and policy landscape addressing inclusion of youth with disabilities within the context of sport, and (2) to identify assets and barriers to inclusive youth sport in Malawi. Findings highlight important contributions of TR and adaptive sport professionals in addressing key legislative and policy priorities in developing countries, while influencing the design, delivery, and evaluation of the exchange program.

\section{Situating the Case: Malawi, Africa}

Malawi is a relatively small landlocked country located in southeast Africa and is among the world's least-developed countries (U.S. Department of State, 2018). There is a lack of current disability prevalence data for Malawi (Mitra \& Sambamoorthi, 2014); thus, we draw upon the most recent report of disability statistics through the 2008 Malawi Housing and Population Census. Although a decade old, these data are commonly used as the foundation for the development of disability-based interventions in Malawi (see Munthali, Tsoka, Milner, \& Mvula, 2013). People with disabilities comprise roughly $3.8 \%(498,122)$ of Malawi's population, with $2.4 \%(159,878)$ of them being children and youth with disabilities. Cultural and social perceptions of disability pose significant challenges for persons with disabilities in Malawi because Africans, in general, attribute causes of disability to witchcraft, juju, sex-linked factors, and divine or supernatural forces (Wa Munyi, 2012). These social myths and misconceptions put Malawian youth with disabilities at risk for discrimination. For example, they are less likely to be in school (18.8\%) as compared to their nondisabled peers (41.1\%), face barriers in accessing health care, and are vulnerable to violence, abuse, neglect, and social isolation (Munthali et al., 2013).

\section{National Legislative and Policy Landscape}

Malawi has a robust legislative and policy framework that appears to adequately address the rights of persons with disabilities (Munthali et al., 2013). The Disability Act of 2012 (Government of Malawi, 2012) and National Policy on the Equalization of Opportunities for Persons with Disabilities of 2006 (Government of Malawi, 2006) both affirm the rights of persons with disabilities to play an equal, full, and participatory role in society. The National Youth Policy of 2013 and National Sports Policy of 2007 (Government of Malawi, 2013) both specifically address the rights of youth with disabilities to equal participation in sport, and require facilities to be accessible to everyone, regardless of ability. The government recognizes the role that sport can play as primary prevention for a variety of public health issues and supports the notion that 
sport can be used as a means to change social attitudes and perceptions around disability. Malawi appears committed to domesticating various international conventions and protocols for the protection of the rights of persons with disabilities. However, multiple challenges still exist with implementation at the local level. As a result, there is a need to build capacity at the local levels to support the government's concern for youth development (Mchombo, 2006), health, and disability rights.

\section{Social Change Through Sport}

Sport has the potential to be a powerful context for both individual and community development (Lindsey, Kay, Jeanes, \& Banda, 2017). Although some research suggests that sport can also have negative effects on developing countries, particularly with respect to "muscle drain" (i.e., migration of talented players and their economic potential overseas) (Andreff, 2004), environmental degradation, and corruption (Jagemann, 2004), these effects were focused on professional-level sports for able-bodied persons, and not on inclusive sport participation for youth with disabilities. While there have been research-based interventions focusing on elite and Paralympic sport development, there is little published intervention work focusing on sport for development at the grassroots level (Schulenkorf, Sherry, \& Rowe, 2016). There are diverse opinions in the research critiquing sport for development efforts, particularly those efforts that are focused on reproducing dominant social relations, rather than focusing on social change and transformation (see Hartmann \& Kwauk, 2011). The YES-Africa Malawi project was conceptualized to help close the gap between elite and grassroots sport development and build capacity of disability sport leaders to increase opportunities for youth with disabilities at the local level.

YES-Africa Sports Exchange Program. In 1961, the Mutual Educational and Cultural Exchange Act was enacted providing the basis and mission for the Bureau of Educational and Cultural Affairs (ECA) in the U.S. Department of State. The purpose of the ECA is to increase mutual understanding between the people of the U.S. and other countries through academic, cultural, sport, and professional exchanges involving both public and private partnerships (ECA, n.d.). Because sport has a universal appeal, particularly for youth, the international sports programming initiative is a popular ECA program designed to "enhance cross-cultural understanding and open new avenues of dialogue and collaboration between individuals and nations" (Notice of Funding Opportunity, 2017, p. 2).

The YES-Africa program centers on positive training of personnel engaged in delivering recreational sport programs for youth, including those with disabilities. Research in youth development emphasizes that the competence of adults involved in youth sports-specifically coaches and parents-creates the largest impact on the developmental potential of the sports experience (Gilbert \& Trudel, 2005). Further, sport for development programs (Coalter, 2013; Lindsey et al., 2017) have long been used as a positive alternative to youth engagement in risky activities such as tobacco use, drug/alcohol abuse, and sexual behavior. Sport is one mechanism for youth with disabilities to find safe environments that promote healthy development alongside peers without disabilities; however, they are often not afforded equal opportunities (Murphy, Carbone, \& Council on Children with Disabilities, 2008). Remedying this discrepancy is critical in the provision of knowledge, skills, and abilities that address sedentary lifestyles for youth with disabilities (Murphy et al., 2008). 


\section{Methods}

A case study method was used to gain an in-depth understanding of the context of inclusive sport and recreation for youth with disabilities in Malawi (Yin, 2003). Case study research is a preferred method when answering "how" or "why" questions in social settings, when the researcher has little control over events being studied, when the subject is a phenomenon in a real-life context, when boundaries between the phenomenon and the context are not clear, and when it is desirable to use multiple sources of evidence (VanWynsberghe \& Khan, 2007).

This case study is framed within an interpretivist paradigm, which assumes that there are many points of entry into any given reality-a reality that is socially constructed as individuals and groups interact and experience the world (Schram, 2003). To arrive at a sound understanding of the case, this case study is not limited to the case in isolation but examines the interaction between the case (e.g., Malawian youth leaders) and its context (e.g., social, political/legislative, cultural, and economic factors in Malawi). The end product is a narrative account that offers new insights into the connections between youth with disabilities, sport and recreation, and inclusion in Malawi.

\section{Setting}

The setting for this case study is the YES-Africa Malawi sport exchange program, which takes place in Malawi, Africa, on the campus of the University of New Hampshire, and throughout the state of $\mathrm{NH}$. Three of the authors traveled to Blantyre, Malawi, in fall 2018 to interview leaders working in the area of sport and disability at the local level. These leaders were identified with the help of three in-country organizational partners - the executive director for a major, international disabled sport organization, the athletic administrator for the medical college at a large national university, and an administrator and public health official working at a local sports academy. Interviews took place with approximately 70 school teachers, public health officials, volunteers, athletes, physiotherapists, and coaches. Of those 70 potential participants, four had disabilities, including two with albinism, and two with intellectual disabilities. Seventeen total participants-nine women and eight men ranging in age between 23 and 50 and representing all three organizational partners-were chosen to participate in the YES-Africa Malawi sport exchange program. Participants hailed from the north, central, and southern regions of the country, with the largest group of participants representing the greater Blantyre region.

\section{Selection of Sample for Case Study}

After obtaining Institutional Review Board approval from the university, we used a purposeful criterion sampling strategy (Patton, 2002) to recruit key informants from the 17 Malawians selected for the exchange to participate in the key informant interview phase of the study. Participants were selected based on the following criteria: (a) 18 years of age or older, (b) spoke and understood English, (c) representative of Malawian sport leaders who serve youth with disabilities, (d) were known to understand the issue and could express perspectives, and (e) voluntarily agreed to participate in one 45-60 minute phone interview in January 2019. Seven of the 17 exchange participants met the inclusion criteria and agreed to participate in the study. 


\section{Data Generation Procedures}

This case study triangulates three data sources (e.g., a crosswalk of legislation and policies on disability, field notes, and key informant interviews) to gain an understanding of the context of inclusive sport programming for youth with disabilities in Malawi.

Crosswalk of legislation and policy in Malawi. A crosswalk of international conventions and documents related to the rights of people with disabilities globally (e.g., U.N.'s SDGs), and Malawi's national laws and policies on sport, youth, and youth with disabilities (e.g., Malawi's Disability Act, National Policy on Equalization of Person's with Disabilities, National Sports Policy, and National Youth Policy) was conducted to examine the alignment of the various frameworks in supporting the rights and protections of persons with disabilities (see Hagan, 2016; Munthali et al., 2013). The crosswalk summary is presented in the introductory sections in order to contextualize the case.

Field notes. Structured field notes were gathered during the first recruitment trip to Malawi by three of the authors in fall 2018. Specifically, field notes were structured in the context of both physical and social environments, and reflected insights and observations gathered during meetings with in-country partners, facility tours, adaptive sport program observation, and during the application vetting process with prospective exchange participants. Field notes also focused on documenting assets and barriers to sport, recreation, and physical activity participation for youth with disabilities at the family, agency, school/community, and regional/national level. Field notes were categorized into general, physical, and social environment observations, and typed up in a Word document for analysis.

Key informant interviews. The third data source was a key informant interview phase, which uses an in-depth interviewing strategy to gather first-hand knowledge about a pressing issue or problem in a given community from a limited number of well-connected and informed community experts who have knowledge about the geographical area, its people, environment, and issues (Kumar, 1986; USAID, 1996). Key informant interviews were used to explore how a representative range of youth leaders perceive inclusive sport, recreation, and physical activity assets and barriers for youth with disabilities in Malawi. A semi-structured interview guide was developed and covered a range of content areas: (a) demographic information; (b) work (or volunteer) experiences in youth-serving agencies, with youth with disabilities, in adaptive sport, recreation, and physical activity service settings; (c) connections and networks with other health professionals serving youth with disabilities; (d) cultural and social perceptions/attitudes towards persons with disabilities; (e) perceived value of sport and recreation as primary prevention and a mechanism to develop health and wellness outcomes; (f) perceptions of assets and barriers to inclusive sport and recreation; and (g) perceptions of research.

To make informed decisions about participants who met inclusion criteria for the key informant interviews, the authors reviewed completed applications from the $17 \mathrm{ex}-$ change participants, and field notes collected during the first site visit to Malawi. Seven of the 17 exchange participants met the inclusion criteria and were invited to participate in the study via email by one of the researchers. Upon receiving informed consent, all seven of the key informants agreed to participate in the interviews that ranged in length from 45-60 minutes. One of the authors conducted all seven key informant 
interviews over the phone and took field notes to supplement and contextualize the interviews. Participants were assigned pseudonyms, interviews were audio-recorded, and transcribed verbatim. A member check procedure was not used due to challenges of international data collection.

\section{Data Analysis Procedures}

Researchers conducted content analysis of all three data sources, in which coding categories were derived directly and inductively from the raw data (Hsieh \& Shannon, 2005). Our content analysis was focused on identifying important themes across the three data sources by providing a rich description of the social reality of inclusive sport and recreation for youth with disabilities in Malawi (Patton, 2002). The content analysis emphasized an integrated review of written contextual text from the crosswalk and field notes, and narrative text from key informant interview transcripts. Researchers individually condensed raw data into categories based on valid inference and interpretation, and then met as a team over the course of four group meetings to simultaneously define and refine the descriptive categories. This process used inductive reasoning, by which themes and categories emerged from the data through the researchers' careful examination and constant comparison (Glaser \& Strauss, 1967). Through careful data preparation, coding, and interpretation, the findings supported the development of a new conceptual model (refer to Discussion).

Creswell's (2018) primary verification procedures for credibility, reliability, and authenticity were employed, as researchers triangulated descriptions and interpretations with each other during the analysis stage. This debriefing process enabled the researchers to utilize multiple sources, perspectives and methods to corroborate the findings, which added credibility to the interpretation process. Alternative explanations to

the conclusions were minimized by triangulating the three data sources, cross checking participants' interviews for inconsistencies and incongruities, and connecting the interview findings to the crosswalk and field note data (Creswell, 2018). Dependability was enhanced by using seven strategically selected key informants, triangulating multiple forms of data, and leaving a field note trail that provided rich description of the context of the case (Creswell, 2018).

\section{Findings}

\section{Participant Demographics}

Key informant interview participants comprised a purposeful sample of seven youth leaders who hold a variety of roles in youth-serving organizations and settings in Malawi (See Table 1). The sample consisted of four females and three males ranging in age from 24 to 46 ; the mean age was 35.42. While it is difficult to know the exact demographic breakdown of youth sport leaders in Malawi, field notes taken during meetings with key stakeholders while visiting in-country suggested that working with youth with disabilities is primarily carried out by women in Malawi. This partially explains the larger number of women in this sample. However, multiple stakeholders indicated the need to encourage more male involvement in disability work-primarily in the area of sport coaching - with the thought that raising the visibility of current male adaptive sport coaches would encourage more men to volunteer or pursue careers working in adaptive sport settings. 


\section{Table 1}

Key Informant Interview Demographics

\begin{tabular}{|l|l|l|l|l|}
\hline Pseudonym & Gender & Age & Role & Organization/Service Setting \\
\hline Beth & Female & 38 & National Director & $\begin{array}{l}\text { International Sport Org for } \\
\text { I/IDD }\end{array}$ \\
\hline Jennifer* & Female & 37 & Research Assistant & $\begin{array}{l}\text { National Public University, } \\
\text { College of Medicine }\end{array}$ \\
\hline Julie & Female & 43 & Professor & $\begin{array}{l}\text { National Public University, } \\
\text { Science \& Technology }\end{array}$ \\
\hline Katie & Female & 46 & Sports Director & $\begin{array}{l}\text { International Sport Org for } \\
\text { I/IDD }\end{array}$ \\
\hline Joe & Male & 25 & Physiotherapist & Pediatric Center \\
\hline Mike & Male & 35 & P.E. Teacher & Secondary School \\
\hline Steve & Male & 24 & $\begin{array}{l}\text { Physiotherapist } \\
\text { Sports Administra- } \\
\text { tor }\end{array}$ & $\begin{array}{l}\text { Central Hospital Community } \\
\text { Basketball Program }\end{array}$ \\
\hline
\end{tabular}

Notes: $I / I D D=$ individuals with intellectual and developmental disabilities; P.E. = physical education * indicates key informant who is serving as an alternate for the YES-Africa sport exchange program

All interview participants were born, raised, and currently live in Malawi. Two participants (Beth, Katie) hold director positions with an international sport organization for individuals with intellectual disabilities; two (Jennifer, Julie) hold positions as a research assistant and professor, respectively, from a national public university; one (Joe) is physiotherapist from a pediatric center; one (Mike) is a physical education teacher) at a secondary school; and one (Steve) holds two roles as a physiotherapist at a central hospital and as a sports administrator at a community-based basketball program. None of the key informants has a disability.

\section{Principle Finding}

The principle finding of this case study suggests that while there is a robust legislative and policy framework that supports social equity around youth, sport, and disability in Malawi, significant implementation challenges still exist throughout the country. While assets that enable inclusive sport for youth with disabilities were identified, broader social, physical, and socio-environmental barriers constrain implementation, scalability, sustainability, dissemination and diffusion. We present a narrative account of three salient themes that emerged from the data.

\section{Theme I: Cultural beliefs and social perceptions of disability constrain youth with disabilities, but attitudes are slowly shifting for the better}

Key informants identified a need for disability awareness and attitudinal change in relation to cultural beliefs and social perceptions of disability. The predominant attitude in Malawi revolves around the notion of disability as something that is the result of witchcraft, evil, or supernatural powers (Wa Munyi, 2012). Field note observations taken during site visits and meetings with program leaders, core volunteers, and pro- 
gram staff during the initial assessment visit in fall 2018 support this notion, suggesting that disability is a significant source of shame and stigma for family members, who often go to great lengths to hide their family member's disability. This attitude appears to result in social exclusion and isolation for youth with disabilities. Katie, a 46-year-old sports director for an international sport organization for individuals with intellectual disabilities (I/IDD) shared this during her interview:

People in Malawi have different levels [of understanding of disability]. Especially in the communities, they have different perceptions and different attitudes. For them to understand what a disability is, there needs to be a lot of sensitization. That is one area where [my organization] is working. People in the village or in the community, they'll take a disability, especially intellectual disability, and they will [misperceive] it as mental illness. Some of them see disability as a result of being bewitched.

Key informants recognized that cultural beliefs and social attitudes toward disability contributed to a devaluing of people with disabilities, ultimately resulting in mistreatment and discrimination. For example, Beth, a 38-year-old national director of an international sport organization for I/IDD traces how cultural beliefs and social misconceptions about disability lead to poor treatment:

The majority [of people in Malawi] feel that they [persons with disabilities] are not equal. They are not normal people. Even after educating them, they still find it hard to accept. But generally before anything else, what they know is that a person with intellectual disability is a cursed person; therefore, does not deserve to be treated properly.

Steve, a 24-year-old physiotherapist at a central hospital and sports administrator in a community basketball program shared this observation: "To a great extent, I can say that people with disabilities are really disregarded in a sense that they are viewed as objects of charity and pity...we usually treat them as lacking or inadequate in some things, which is not right." Joe, a 25 -year-old physiotherapist from a pediatric center concurred, as he shared these thoughts related to his community's limited knowledge about the abilities and strengths of people with disabilities:

A lot more people think people with disabilities are not as productive as another person, that they cannot participate in activities that are happening in their communities. They are not productive individuals, do not deserve education, or job opportunities. So, if you ask about the perception [of disability] in my community, there are people who still think there is something that gets in the way for people with disabilities.

Key informants described the resulting social isolation that accompanies these misconceptions. Jennifer, a 37-year-old research assistant from a public university in Malawi noted, "...most of the times those kids [with disabilities] are left on the margin, and not included in anything; whether it be sports, whether it would be any other 
extracurricular activities." She went on to say, "Most people that I see with disabilities, I see them on the street begging. I feel like already, that's kind of how they see themselves. Because as a society, that's what we've said they are." Katie shared a similar sentiment when reflecting on the consequences of negative societal attitudes: "A lot of them have dropped out of school because of the different attitudes from their peers or even other people in the community. Some of them are laughed at when they are in school."

While participants were clear about the disadvantages associated with negative social perceptions, they were hopeful for what they perceived as slight attitudinal "shifts" that appear to be occurring in the country. For example, Beth noted,

... [the work that our organization does] is basically awareness...it's about changing the community's mind-set, and changing other people who still feel like [people with disabilities] don't deserve to be given equal opportunities to participate in sports. So basically it's awareness, awareness, awareness until we get to a point where everybody accepts them and then they're able to participate and use the facilities.

Steve reiterated this gradual progressive nature of acceptance and inclusion, as he pointed to the use of "improvisation" as one potential mechanism of social change in communities. He noted,

I see that these [sport] organizations that we have in Malawi are particularly [drawn to] improvisation, and that is one of the factors that may have led to maybe some very slow development in that area of inclusion, because we want sport for people with disability to develop pretty much in the same way that the sport for people without disability has developed.

Steve's insight suggests that youth sport leaders in Malawi are learning to adapt to social constraints by remaining open to change and incorporating flexibility, creativity, and resourcefulness in their efforts to combat social constraints. Field note observations gathered during a visit to a boys under-17 Unified football (soccer) match illustrated this sense of flexibility and openness to change. The match was well attended by youth and adults in the local community, and the head referee of the match was a 16-year-old female with an intellectual disability. This scenario suggests that youth with disabilities engaged in sport are slowly being recognized and valued at the community level. Malawi has taken steps to domesticate international protocols focusing on disability rights, and has developed its own legislative and policy agenda in this area. As a result, there appears to be some hope that attitudes towards disability and society's broader perceptions of youth with disabilities can change.

\section{Theme II. Limited access in the physical environment persists for youth with disabilities in Malawi}

Despite national legislation and policies protecting against inequality in access to the physical environment barriers still persist for youth with disabilities. Key informants identified lack of access to transportation, housing, and public spaces (e.g., sport, healthcare, educational facilities) as key barriers for youth with disabilities to 
access adaptive sport opportunities. Field note observations during site visits with program leaders in Malawi consistently noted that access to suitable sport facilities was one of the most significant barriers to increasing adaptive sport opportunities. Even when facilities are available, they rarely meet standards of accessibility. Schools are critical spaces where youth with disabilities have access to physical education, extracurricular and sport activities. However, as Steve observed during his key informant interview, barriers in the healthcare and educational arenas continue to limit full inclusion for youth with disabilities:

I still see hospitals not really [being] adequately accessible... and most of the schools that we have in Malawi are not really accessible from a physical aspect. It would be very hard for a child with disability to easily walk to school. They may be able to walk to the school, but they may not be able to easily walk around the school. These issues of accessibility are impacting a lot of people.

Beth made a connection between the social devaluing of people with disabilities and discrimination in equitable use of sports facilities: "When it comes to using their [sports] facilities, first preference is given to people without a disability. So already they [people with disabilities] are discriminated against, and they can't fight. At the end of the day, it's either they are able to use the resources or only at a minimal [level]." Joe, a 25-year-old physiotherapist from a pediatric center agreed:

The major [barrier], I would say from my standpoint is the lack of serious sporting facilities in the country...in Malawi when we look in our communities, we do not have such facilities, because they are only for the able-bodied people, or [renovations] are made [to the facilities], but that still does not really make them fully accessible.

Field note observations made during the in-country visit indicated that sport opportunities for youth with disabilities often take place in public spaces, such as schools, colleges and universities, and at community fields or clubs. In addition to challenges with accessibility, youth leaders consistently noted that programs serving youth with disabilities often struggle to reserve field or court time for practices and games, receive less-than-desirable reservation times, or get bumped from their reservations in favor of other user-groups. Many of these issues are exacerbated by the lack of accessible transportation systems that make traveling to and from sporting events a significant barrier for those with disabilities. For example, Jennifer discussed the consequences of inaccessible public buildings and transportation in relation to loss of independence and confidence for people with disabilities,

....some of our public buildings - whether it be the library or places of entertainment or even sports facilities-people with disabilities can't access. Even like the public transportation, the most common form of public transportation here is the mini-buses. I've never seen one that a person with disabilities can fully access without help...even just getting to places, [people with disabilities] have to have someone with them, so it kind of takes away their independence, and similarly, their confidence. 
In sum, key informant interviews and field note observations reflect the fact that the physical environmental context in Malawi, particularly the lack of accessible facilities and environmental supports, may moderate the effects of inclusive sport programming. Despite Malawi's legislative and policy framework (Disability Act; National Policy on the Equalization of Opportunities for Persons with Disabilities; National Youth Policy; \& National Sports Policy) which affirms the rights of persons with disabilities to play an equal, full, and participatory role in society, implementation and monitoring of those laws and policies in relation to the built and natural environment is still lagging behind.

\section{Theme III. Barriers in the socio-environmental context constrain providers of inclusive sport for youth with disabilities in Malawi}

Key informants suggested that they felt constrained in their attempts to provide inclusive sport by constraints in the socio-environmental context, such as barriers in human, financial, and equipment resources; fragmented interagency coordination and networking structures; and limited evidence-based monitoring and evaluation of legislative and policy implementation efforts. For instance, Katie shared observations about limited sports programs and equipment resources in remote communities in Malawi:

[We should start sports programs] in the remote areas and people in the community will really, really appreciate [that]. I'm looking forward to see[ing] support with a lot of equipment because in Malawi there are playgrounds, but a lot of equipment (for example, soccer balls) is not durable. So if there is no equipment, then the people in the community, they'll say, no, we will not do this activity because we don't have equipment.

Steve similarly felt constrained by a shortage of equipment, facilities, and adaptive sport expertise among service providers:

...among other minor challenges like shortage of equipment, or lack of expertise in that sport, the biggest challenge is the facilities. We do not have the proper facilities, and this does not only apply to people with disabilities, but also people without disability. [If] sports facilities are not in good shape, then real sports development cannot take place.

Many participants noted challenges associated with a lack of a centralized organization to coordinate the diverse range of youth-sport serving agencies/programs in Malawi. In reflecting upon the critical nature of collaboration, partnerships, and networking in her sport organization, Katie commented:

It's about cooperation, networking, and also understanding the role of partnership. On our own, we cannot do it all. On our own, we cannot do anything. [We] need to work with other partners, for them to promote, if it's health issues for people with intellectual disabilities...if it's education, it's the Ministry of Education. It's about child health, child rights. It's about social welfare and all other areas. It's what we do. It's all what [my organization] does. 
One of the challenges identified with developing these partnerships is the lack of a defined community of practice related to adaptive sport in Malawi. Field notes taken during the in-country assessment visit in fall 2018 suggested that there are few systems and little integration of efforts, and while there is a patchwork of providers of adaptive sport opportunities for youth with intellectual and physical disabilities spanning the education, health care, and nonprofit sectors, these groups do not appear to be working together in a coordinated way. Program directors noted the need for more networking and sharing opportunities among adaptive sport volunteers, coaches, and staff.

Further, field note observations gathered during discussions with program leaders consistently suggested that there were issues with the "volunteer culture" in Malawi. For example, program directors from different organizations discussed the challenge of selling the benefits of volunteering for youth with disabilities to potential coaches and youth sport leaders. As financial resources are limited in Malawi, program directors stated that adults must spend most of their time providing for their families, making volunteerism difficult. As one program director stated, "Volunteer coaches in particular will move on from adaptive sport when they build experience and can move on to paid opportunities in other areas of the sport industry." Because of this trend, systems for training and development of volunteers are limited or nonexistent. Field note observations suggested that this was the case for paid staff as well, as program directors consistently pointed to a lack of formalized education opportunities for adaptive sport coaches.

Key informant interview data also pointed to barriers in the monitoring and evaluation of legislative and policy implementation efforts among youth sport leaders and coaches. For example, Julie, a 43-year-old professor at a public university in Malawi contributed this insight during her interview:

Implementation of policy in the sports industry hasn't been good; actually, it is on a slow pace. People are having problems implementing it, and the major problems are because most haven't seen or even read the document [National Policy on the Equalizations of Opportunity for Persons with Disabilities], and maybe [don't] understand what is there.

The crosswalk of legislative, sport, and disability policy revealed the need for ongoing monitoring and evaluation of implementation efforts across the country. For example, the National Policy on the Equalization of Rights for Persons with Disabilities (2006) specifically suggests, "implementation is contingent on cooperation and integration of efforts with both governmental and non-governmental organizations" (p. 35). However, the policy document recognizes the "lack of capacity" among organizations in the disability sector to adequately engage in such efforts.

Although numerous barriers were identified in the socio-environmental context, Steve was able to point to assets that he viewed as having potential to address some of these barriers. His optimism was noted in this interview comment:

Here in Malawi we see a lot of young people with disabilities willing to participate in sport, and I think that's the first best resource. Number two, we have a lot of land in which [sport] structures can actually be set up. We have a lot of land in Malawi. That is a resource that can actually facilitate achievement 
of our [sport] needs. In addition, we have projects and government organizations in Malawi that are working to promote the welfare of people with disabilities. We have people that are winning on the ground. That's a vital resource that can actually be used in terms of partnerships.

\section{Discussion}

The principle finding of this case study is that while Malawi appears to have a legislative and policy framework supporting the rights of persons with disabilities, there are still significant barriers to implementation at the local level (Hagen, 2016; Munthali et al., 2013). Implementation challenges, including the lack of resources, interagency coordination, training and development of staff, development of networks of information sharing among sport professionals, and the lack of effective monitoring and evaluation are widely recognized and well documented (Munthali et al., 2013). While sport leaders and coaches appear to be working on disability issues at the grassroots level, many, including persons with disabilities themselves, are largely unaware of legislative and policy documents, or the specific rights afforded by them. The issue of awareness of rights is a significant one. If one has rights but is not aware that those rights exist, or the recourse that one is due when rights are violated, then the practical utility of government policy documents to people on the ground is of little value. To fully implement the legislative and policy framework that expands sport opportunities for youth with disabilities, youth leaders must be aware that such documents exist.

Another significant finding was the key role that cultural and social perceptions play in marginalizing persons with disabilities. One way to address negative social attitudes is to change the conversation about disability. Acceptance can be built through social situations, and leisure engagement is one such opportunity for the development of social acceptance (Mobily, Walter, \& Finley, 2015). Inclusive sport has the potential to address many of the disparities experienced by youth with disabilities, and may be the area of life where the opportunity for social acceptance is most prevalent (Devine, Piatt, \& Dawson, 2015). As communities remove barriers and enable sport opportunities for everyone, including youth with disabilities, progress and acceptance may become more evident in other social areas such as health care, education, and employment. Interestingly, this pattern mirrors what happened in the U.S. during deinstitutionalization and the disability rights movement in the 1960s and 70s. During deinstitutionalization, people with disabilities were discriminated against in many areas of society because the outside world was not prepared with accessible facilities, programs, resources, trained staff, or the social attitudes to support persons with disabilities (Bullock \& Mahon, 2017). A more contemporary 'parallel' movement started in 2003, when the U.S. and European countries acknowledged the potential role of the socio-environmental and policy context in supporting behavior change. This led to changes in grant funding for research on environmental correlates of behavior, and motivated a whole new generation of research that is now being used to inform practice (Sallis 2006; 2012).

Our findings reveal considerable intersectionality related to the international and national legislative and policy landscape, and the potential of inclusive sport to affect society at multiple levels. These intersections are shown in Figure 1, which is adapted from the work of McLinden et al. (2018) and grounded in Bronfenbrenner's (1977) bioecological systems theory. 


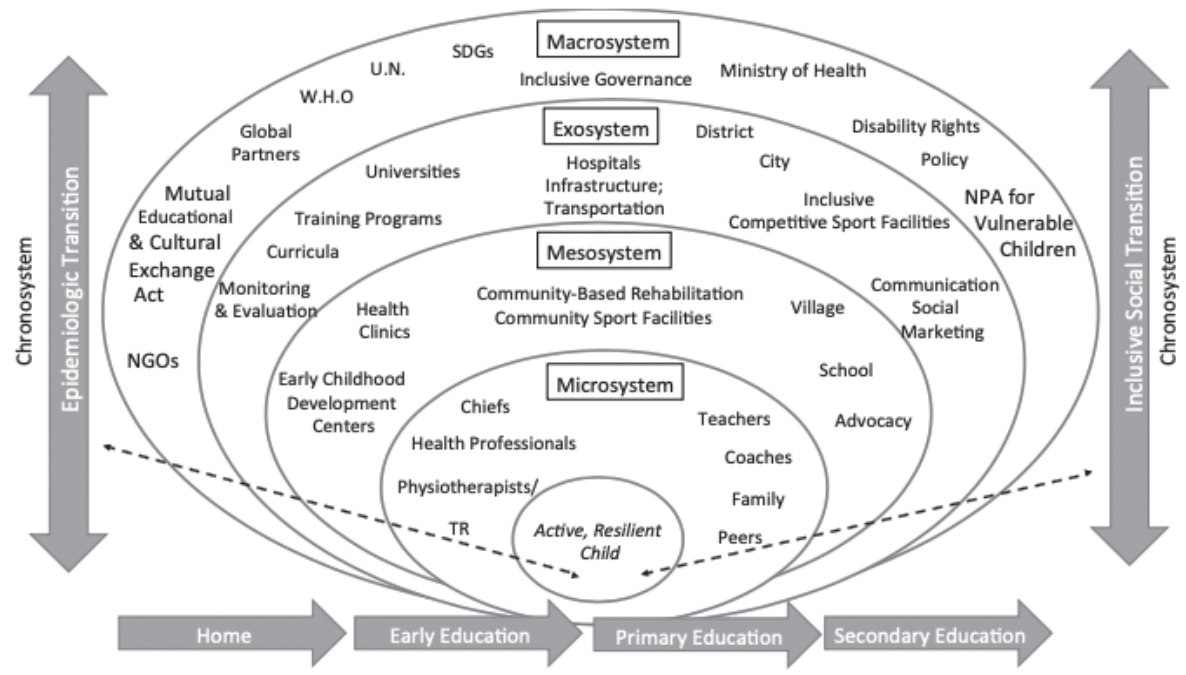

Figure 1. Socio-Ecological Model of Inclusive Sport in Malawi, Africa

Note: Adapted from McLinden, et al. (2018). Supporting children with disabilities in low- and middle-income countries: Promoting inclusive practice within community-based childcare centres in Malawi through a bioecological systems perspective. International Journal of Early Childhood, 50, 159-174. (c) The Author(s) 2018

At the center of the figure is the active, resilient child (intrapersonal level) who is surrounded by concentric spheres of influence that can be leveraged to create an inclusive ecological context. These spheres include the microsystem (the child's interpersonal relationships and social supports); the mesosystem (local community resources); the exosystem (regional organizations and institutions); and the macrosystem (national and international legislative and policy landscape; governance structures). Relating this conceptual figure back to our findings, interviewees described key individuals within the child's microsystem that influence youth participation in sport and civic life, including teachers, coaches, physiotherapists, peers, and village chiefs who are often viewed as "gatekeepers" of village life. At the mesosystem level, triangulation of data from interviews, field notes, and legislative/policy documents revealed that community institutions such as community-based rehabilitation centers, sports facilities, schools, health clinics, and childcare centers were key settings in which inclusive norms and practices could be implemented. While lack of resources continues to be a difficult challenge, a goal of the YES-Malawi sport exchange program is to train key individuals who work in these settings to advocate for inclusion and use the existing resources most effectively. YES-Malawi participants also include representatives from the exosystem and macrosystem (e.g., Ministry of Health, university researchers) who can serve as conduits for communication across the systems and disseminate the lessons learned, thus helping to support implementation of inclusive policies.

Three interrelated chronosystems, or time vectors, are also depicted in Figure 1. The first vector at the bottom of the figure is the child's developmental process, as he/ she progresses through school and across the life-course. The second vector on the right side of the figure is Malawi's social transition. Our findings suggest that while 
Malawi aspires to be an inclusive society in which persons with disabilities have equal opportunities, the country is currently in its infancy of that transition, and stakeholders recognize that it will take time. Malawi has adopted many policies that are oriented toward inclusion, but implementation has been challenging and social stigma is still pervasive. Creating communities of practice and communication networks across systems can help to foster vertical and horizontal integration for more inclusive governance.

Lastly, as in many developing countries, Malawi is in the midst of an epidemiologic transition (the third vector on the left side of the figure) that includes high rates of non-communicable diseases concurrent with increasing rates of Western chronic diseases (e.g., cardiovascular disease). This transition affects children, both in terms of the causes of disability (e.g., birth conditions, childhood infectious disease) as well as their development over the life course. It also has profound implications or "feedbacks" to the macrosystem, such that active children will make the meso- to macrosystems more resilient to chronic disease over time. This reflects a blend of bioecological theory and socioecological systems theory (Sallis, 2006). For example, the Ecological Model of Physical Activity developed by Sallis et al. (2012) reflects over a decade of research on correlates of physical activity, obesity, and cardiovascular disease. Four levels of influence are emphasized: (1) the policy environment, (2) the built environment, (3) the social/cultural environment, and (4) individual-level factors such as skills and psychological attributes. We contend that environmental, policy, and normative changes are needed to complement individual education efforts in order to create widespread and sustainable effects. Partnerships that can build capacity across multiple domainsincluding leisure, sport, school, infrastructure, and civic life-may be more likely to support positive development at both individual and collective levels. The YES-Africa Malawi sport exchange program is designed to facilitate this process.

\section{Limitations}

This study had several limitations, and conclusions should be considered with these in mind. First, all seven of the key informant interviews were conducted by one interviewer. While consistency of the interviewing method was likely enhanced by the use of one interviewer, there is the possibility that personal biases and assumptions influenced the interview process. Further, while efforts were made to ensure that key informants were representative of the YES-Africa Malawi exchange cohort, the seven participants were primarily from Blantyre area in the southern region of the country and reflect a narrow slice of those working on behalf of youth with disabilities. The methods employed in this study do not allow for generalizability of the findings to the larger disability sport community in Malawi. Finally, voices in this study were those of sport leaders working on behalf of those with disabilities. Including the perspectives of youth who may face stigma, prejudice, or other physical and socio-environmental barriers to sport participation would have provided a different lens through which to view the progress of legislative and policy implementation in Malawi.

\section{Implications for TR Practice}

According to the ECA at the U.S. Department of State, "sports-based people-topeople exchanges are central to building and promoting values of inclusion and open opportunities for people to contribute fully to society, and create opportunities to es- 
tablish the trust needed to build a more stable, secure, and prosperous world" (Notice of Funding Opportunity, 2017, p. 2). Therapeutic recreation and adaptive sport professionals are well positioned to advance the international dialogue around disability rights through the use of inclusive sport that can address the ECA's charge and align with many of the U.N.'s policy goals for persons with disabilities in a global context.

These initial case study outcomes may be fruitful for future TR or adaptive sport exchange programs focused on marginalized populations at home or abroad. For example, although a considerable body of research on the socio-environmental and human rights correlates of sport participation has been generated in Western countries over the past decade (Rimmer et al., 2004; Sallis et al., 2012), a richer evidence base is needed to inform culturally sensitive interventions in developing nations. By involving professionals from developing countries as change agents, research-practice partnerships such as the YES-Africa program can begin to generate this evidence.

While our findings show evidence of a diverse, dedicated, and motivated group of youth sport leaders in Malawi, they appear to be working without a central organizing network or set of best practices to guide their work. Therapeutic recreation may very well be the bridging "vehicle" through which central coordination and networking can occur. Introducing the TR profession to Malawi would be a practical outcome of this study. Additionally, while youth sport leaders recognize domain-specific benefits of sport for youth with disabilities, current programs fall primarily within the recreation participation arena. With targeted education and training during the YES-Africa exchange, youth sport leaders can learn to utilize leisure education to empower youth with disabilities and provide functional interventions that address a diverse range of health outcomes of participation.

\section{Implications for Future Research}

This case study provides a rich description of the social reality of inclusive sport for youth with disabilities in Malawi. Findings have informed our understanding of the motivations, perspectives, and behaviors of youth leaders who currently provide sport for youth with disabilities in Malawi. Findings have also guided our decision-making and generated recommendations for the YES-Africa Malawi program, and are helping us design future research questions.

This case study is the first phase of a larger outcomes study of the YES-Africa Malawi program. We are currently in the process of designing pre and posttest evaluation of the exchange program. Future participatory action research, such as a photovoice method, may take into account the unique perspectives, motivations, and attitudes of Malawian youth with disabilities who regularly experience social, physical, and socioenvironmental barriers to community participation and engagement.

\section{References}

Andreff, W. (2004). The taxation of player moves from developing countries. In R. Fort \& J. Fizel (Eds.), International sports economics comparisons (pp. 87-103). Westport, CT: Praeger.

Beqiraj, J., McNamara, L., \& Wicks, V. (2017). Access to justice for persons with disabilities: From international principles to practice. International Bar Association. Retrieved from Bingham Centre for the Rule of Law, www.binghamcentre.biicl.org 
Brolan, C. (2016). A word of caution: Human rights, disability, and implementation of the post-2015 Sustainable Development Goals. Laws, 5(2), 1-18. doi:10.3390/ laws5020022

Bronfenbrenner, U. (1977). Toward an experimental psychology of human development. American Psychologist, 32, 513-532.

Bullock, C. C., \& Mahon, M. J. (2017). Introduction to recreation services for people with disabilities: A person-centered approach. Urbana, IL: Sagamore-Venture.

Bureau of Educational and Cultural Affairs (n.d.) About ECA. Washington, D.C.: United States Department of State. Retrieved from http://eca.state.gov

Coalter, F. (2013). Sport for development: What game are we playing? New York, NY: Routledge.

Creswell, J. (2018). Research design: Qualitative, quantitative, and mixed-methods approaches (5th ed.). Thousand Oaks, CA: Sage Publications.

Devine, M. A., Piatt, J., \& Dawson, S. L. (2015). The role of a disability-specific camp in promoting social acceptance and quality of life for youth with hearing impairments. Therapeutic Recreation Journal, 49(4), 293-309.

Gilbert, W. D., \& Trudel, P. (2005). Role of the coach: How model youth team sports coaches frame their roles. Sport Psychologist, 18(1), 21-43.

Glaser, B. G., \& Strauss, A. L. (1967). The discovery of grounded theory: Strategies for qualitative research. Chicago, IL: Aldine Transaction Publishers.

Government of Malawi. (2006). National Policy on Equalization of Opportunities for Persons with Disabilities. Ministry of Persons with Disabilities and the Elderly. Retrieved from http://usicd.org/doc/MWI104037.pdf

Government of Malawi. (2012). Malawi Disability Act. Retrieved from http://www. fedomamalawi.org/public/themes/Fedoma/downloads/Disability_Act_2012.pdf

Government of Malawi. (2013). National Youth Policy. The Ministry of Youth and Sports. Retrieved from http://www.youthpolicy.org/national/Malawi_2013_National_Youth_Policy.pdf

Government of Malawi. (2018). Journey of life: Community awareness and mobilization tool in achieving child protection results in Malawi. The Ministry of Gender, Children, Disability and Social Welfare. Retrieved from https:/www.unicef.org/ malawi/reports/journey-life-review-report

Hagen, C. (2016). Barriers to education for youth with disabilities in Malawi: A qualitative study of policy and practice in urban and rural areas (Unpublished masters thesis). Norwegian University of Life Sciences, As, Norway.

Harada, C. M., \& Siperstein, G. N. (2009). The sport experience of athletes with intellectual disabilities: A national survey of Special Olympics athletes and their families. Adapted Physical Activity Quarterly, 26, 68-85. doi:10.1123/apaq.26.1.68

Hartmann, D., \& Kwauk, C. (2011). Sport and development: An overview, critique, and reconstruction. Journal of Sport and Social Issues, 35(3), 284-305. doi:10.1177/0193723511416986

Hsieh, H. F., \& Shannon, S. E. (2005). Three approaches to qualitative content analysis. Qualitative Health Research, 15(9), 1277-1288.

International Platform on Sport and Development. (2009). Thematic profile: Disability sport and adapted physical activity (print version). Retrieved from www.sportanddev.org 
Jagemann, H. (2004). Sports and the environment: Ways towards achieving the sustainable development of sport. The Sport Journal, 20. Retrieved from http://thesportjournal.org/article/sports-and-the-environment-ways-towards-achievingthe-sustainable-development-of-sport/

Kumar, K. (1986). Conducting key informant interviews in developing countries. USAID Center for Development Information and Evaluation (AID Program Design and Evaluation Methodology, Report no.13, PN-AAX-226).

Lindsey, I., Kay, T., Jeanes, R., \& Banda, D. (2017). Localizing global sport for development. Manchester, UK: Manchester University Press.

Lundberg, N., Taniguchi, S., McCormick, B., \& Tibbs, C. (2011). Identity negotiating: Redefining stigmatized identities through adaptive sports and recreation participation among individuals with a disability. Journal of Leisure Research, 43(2), 205225. doi:10.1080/00222216.2011.11950233

Mchombo, S. (2006). Sports and development in Malawi. Soccer in Society, 7(2-3), 318-338.

McLinden, M., Lynch, P., Soni, A., Artiles, A., Kholowa, F., Kamchedzera, E.,... Mankhwazi, M. (2018). Supporting children with disabilities in low- and middle-income countries: Promoting inclusive practice within community-based childcare centres in Malawi through a bioecological systems perspective. International Journal of Early Childhood, 50, 159-174. doi:10.1007/s13158-018-0223-y(0123456789().,

Mitra, S., \& Sambamoorthi, U. (2014). Disability prevalence among adults: Estimates for 54 countries and progress toward a global estimate. Disability and Rehabilitation, 36(11), 940-947. doi: 10.3109/09638288.2013.825333

Mobily, K. E., Walter, K. B., \& Finley, S. E. (2015). Deconstruction of TR/RT: Does TR/RT contribute to the negative construction of disability? Part I, World Leisure Journal, 57(1), 46-56. doi:10.1080/16078055.2014.1001176

Munthali, A., Tsoka, M., Milner, J., \& Mvula, P. (2013). From exclusion to inclusion: Promoting the rights of children with disabilities in Malawi. Retrieved from https:// www.unicef.org/malawi/resources_12771.html.

Murphy, N. A., Carbone, P. S., \& Council on Children with Disabilities (2008). Promoting the participation of children with disabilities in sports, recreation, and physical activities. Pediatrics, 121(5), 1057-1061. doi: 10.1542/peds.2008-0566.

Notice of Funding Opportunity. (2017, March 17). FY 2017 International Sports Programming Initiative. Washington, D.C.: Bureau of Educational and Cultural Affairs, United States Department of State.

Patton, M. Q. (2002). Qualitative research and evaluation models. Thousand Oaks, CA: Sage.

Rimmer, J. H., Riley, B., \& Wang, E. et al. (2004). Physical activity participation among persons with disabilities: Barriers and facilitators. American Journal of Preventative Medicine, 26(5), 419-425.

Rimmer, J. H., Rowland, J. L., \& Yamaki, K. (2007). Obesity and secondary conditions in adolescents with disabilities: Addressing the needs of an underserved population. Journal of Adolescent Health, 41(3), 224-229. doi: 10.1016/j.jadohealth.2007.05.005.

Sallis, J. F., Cervero, R. B., Ascher, W., Henderson, K. A., Kraft, M. K., \& Kerr, J. (2006). An ecological approach to creating active living communities. Annual Review of Public Health, 27, 297-322. [PubMed:16533119] 
Sallis, J. F., Floyd, M., Rodriguez, D., \& Saelens, B. (2012). The role of built environments in physical activity, obesity, and CVD. Circulation, 125(5), 729-737. doi:10.1161/ CIRCULATIONAHA.110.969022.

Schram, T. H. (2003). Conceptualizing qualitative inquiry: Mindwork for fieldwork in education and the social sciences. Upper Saddle River, NJ: Pearson Education, Inc.

Schulenkorf, N., Sherry, E., \& Rowe, K. (2016). Sport for development: An integrated literature review. Journal of Sport Management, 30, 22-39.

Sherrill, C., \& Williams, T. (1996). Disability and sport: Psychological perspectives on inclusion, integration, and participation. Sport Science Review, 5(1), 42-64.

Struthers, P. (2011). The use of sport by a health promoting school to address community conflict. Sport in Society, 14, 1251-1264. doi: 10.1080/17430437.2011.614782

Sustainable Development Goals Fund. (2018). The contribution of sports to the achievement of the Sustainable Development Goals. New York: U.N. Retrieved from http:// www.sdgfund.org/sites/default/files/report-sdg_fund_sports_and_sdgs_web_0. pdf

United Nations. (2006). Convention on the Rights of Persons with Disabilities. New York, NY: U.N. Retrieved from www.un.org/disabilities.

United Nations. (2016). Sustainable development goals: Localisation, opportunities, and challenges for Malawi. New York: U.N. Retrieved from https://mw.one.un.org/ sdgs-malawi/

United States Department of State. (2018). Bureau of African Affairs fact sheet: U.S. relations with Malawi. Retrieved from https://www.state.gov/r/pa/ei/bgn/7231.htm

USAID Center for Development Information and Evaluation. (1996). Conducting key informant interviews: Performance monitoring \& evaluation tips. Washington, DC: USAID. Retrieved from http://pdf.usaid.gov/pdf_docs/PNABS541.pdf

VanWynsberghe, R., \& Khan, S. (2007). Redefining case study. International Journal of Qualitative Methods, 6(2), 1-10. Retrieved from http://www.ualberta.ca/ iiqm/ backissues/6_2/vanwynsberghe.htm

Wa Munyi, C. (2012). Past and present perceptions towards disability: A historical perspective. Disability Studies Quarterly, 32(2), doi: 10.18061/dsq.v32i2.3197

Wilhite, B., \& Shank, J. (2009). In praise of sport: Promoting sport participation as a mechanism of health among persons with a disability. Disability and Health Journal, 2, 116-127. doi:10.1016/j.dhjo.2009.01.002

World Health Organization \& World Bank. (2011). World report on disability. Geneva: WHO. Retrieved from http://whqlibdoc.who.int/publications/2011/9789240685215_eng.pdf

Yin, R. K. (2003). Applications of case study research. Thousand Oaks, CA: Sage. 
Copyright of Therapeutic Recreation Journal is the property of Sagamore Publishing and its content may not be copied or emailed to multiple sites or posted to a listserv without the copyright holder's express written permission. However, users may print, download, or email articles for individual use. 